УДК 541.9

\title{
ХИМИЧЕСКИЙ СОСТАВ И ЛЕЧЕБНЫЕ СВОЙСТВА НАФТАЛАНСКОЙ НЕФТИ
}

\section{Субханкулова Эмилия Ильдаровна}

ФГБОУ ВО «Башкирский государственный университет»

\begin{abstract}
Аннотация. В настоящей работе описываются общие характеристики нафталанской нефти, проведено исследование лечебных свойств и химического состава молодой нефти, которую давно используют в медицинских целях, и выделенных из нее компонентов. Приведен структурно-групповой и элементарный состав групп углеводородов нафталанской нефти.

Ключевые слова: нафталанская нефть, химический состав, нафталан, лечебные свойства.

\section{CHEMICAL COMPOSITION AND MEDICINAL PROPERTIES OF NAFTALAN OIL}

\section{Subkhankulova Emilia Ildarovna}

Abstract. This work describes the general characteristics of Naftalan oil, studies the medicinal properties and chemical composition of young oil, which has long been used for medical purposes, and the components isolated from it. The structural-group and elementary composition of the groups of hydrocarbons of Naftalan oil is given.

Key words: naphthalan oil, chemical composition, naphthalan, medicinal properties.

\section{Введение}

Нафталановая нефть - сорт лечебной нефти, имеющий сиропообразную консистенцию коричневого или темно-коричневого цвета с оливковым оттенком и своеобразным нефтяным запахом. Месторождение этой нефти находится вблизи города Нафталан (Азербайджан).

Нафталан - фактически первичный продукт или молодая нефть, давно используют в медицинских целях, однако до сих пор не ясно, какие из ее компонентов обладают наибольшей биологической активностью. 
В 13 веке впервые упомянул о лечебной нафталанской нефти Марко Поло, путешествующий по Азербайджану: «...там есть большой колодец с маслянистым веществом, которым можно навьючить много верблюдов. Оно употребляется не для питания, а для смазывания при кожных заболеваниях у людей и скота, равно как и при других недугах».

Она используется при заболеваниях кожи, нервной системы, опорнодвигательного аппарата, гинекологических заболеваниях и так далее. Нафталанолечение - является разновидностью теплового лечения. Сама нефть и изготовленные из неё препараты применяются в виде нафталановых повязок, ванн, местного смазывания в сочетании со свето- и электролечением.

\section{Цель работы}

Целью данной научной работы является изучение, посредством теоретических исследований, химического состава и лечебных свойств нафталанской нефти.

\section{Состав лечебной нафталанской нефти}

Широкое применение лечебной нафталанской нефти в мед практике требует тщательного изучения входящих в её состав компонентов.

Результаты исследований [1] по разделению нафталановой нефти на части и изучению её состава методом адсорбционной хроматографии на силикагеле представлены на следующем графике:

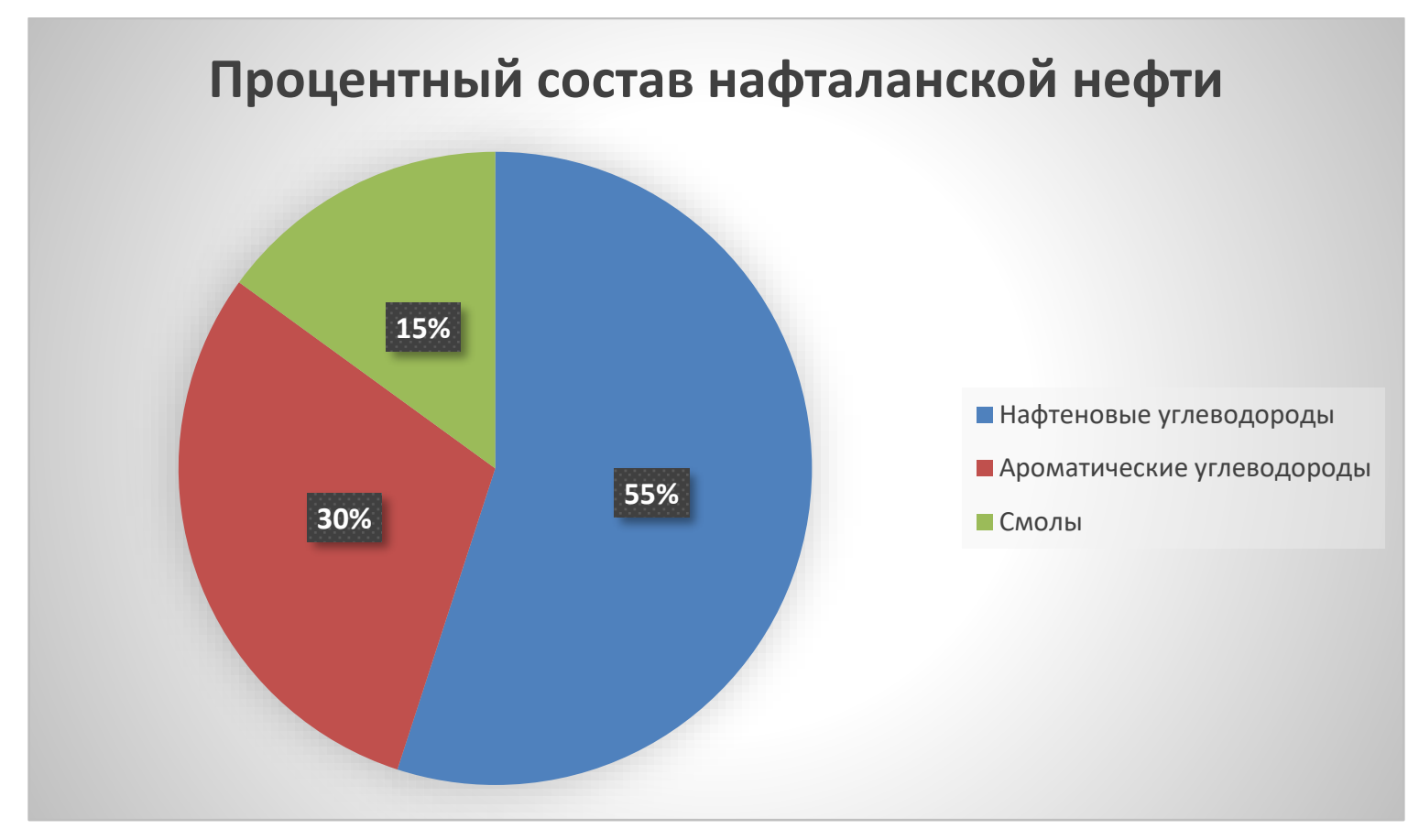

Рис. 1. Процентный состав нафталанской нефти 
Высокой цикличностью молекул и преобладанием углеродных атомов в кольчатых структурах отличаются нафтеновые и ароматические группы углеводородов.

Результаты депарафилизации цеолитом, карбамидом и в растворе селективных растворителей показали, что она состоит из циклопарафиновых углеводородов, в ней отсутствуют твёрдые парафиновые углеводороды.

Выделенная из нафталанской нефти широкая фракция нафтеновых углеводородов подверглась вакуумной перегонке на узкие фракции с разной выкипаемостью для упрощения состава. Благодаря наличию данных по синтезу высокомолекулярных соединений, разделение на такие малые фракции обуславливается тем, что в выбранные пределы температур кипения укладываются индивидуальные углеводороды различных классов[5].

\section{Таблица 1}

\section{Результаты вакуумной перегонки широкой фракции нафтеновых углеводородов нафталанской нефти и анализ полученных фракций}

\begin{tabular}{|c|c|c|c|c|}
\hline \multirow{3}{*}{$\begin{array}{c}\text { Пределы } \\
\text { кипения, }{ }^{0} \mathrm{C}\end{array}$} & \multirow[t]{3}{*}{ Нефть } & \multicolumn{3}{|c|}{ Структурно-групповой анализ по методу n-d-M } \\
\hline & & \multirow[t]{2}{*}{ число колец Ко } & \multicolumn{2}{|c|}{ доля углеродных атомов, \% } \\
\hline & & & в кольцах & в цепях \\
\hline \multirow[t]{5}{*}{$350-420$} & Гюргянская & 2,3 & 45 & 55 \\
\hline & Косчагыльская & 1,9 & 39 & 61 \\
\hline & Грозненская & 1,6 & 34 & 66 \\
\hline & Ромашкинская & 1,7 & 36 & 64 \\
\hline & Нафрталанская & 2,7 & 59 & 41 \\
\hline \multirow[t]{4}{*}{$420-450$} & Гюргянская & 3,1 & 44 & 56 \\
\hline & Грозненская & 2,6 & 45 & 55 \\
\hline & Ромашкинская & 1,9 & 33 & 67 \\
\hline & Нафрталанская & 3,1 & 53 & 47 \\
\hline \multirow[t]{3}{*}{$500-525$} & Гюргянская & 3,4 & 38 & 62 \\
\hline & Косчагыльская & 2,6 & 28 & 73 \\
\hline & Нафрталанская & 3,6 & 58 & 42 \\
\hline \multirow[t]{2}{*}{ выше 525} & Гюргянская & 3,3 & 32 & 67 \\
\hline & Нафрталанская & 3,8 & 50 & 50 \\
\hline
\end{tabular}

Сопоставить состав фракций нафталановой нефти с соответствующими депарафинированными фракциями других нефтей, позволят изученные аналогичные фракции нафтеновых углеводородов ряда других нефтей [1]. 


\section{Таблица 2}

\section{Состав фракций нафтеновых углеводородов различных нефтей}

\begin{tabular}{|c|c|c|c|c|}
\hline \multirow{3}{*}{$\begin{array}{c}\text { Пределы } \\
\text { кипения, }{ }^{0} \mathrm{C}\end{array}$} & \multirow[t]{3}{*}{ Нефть } & \multicolumn{3}{|c|}{ Структурно-групповой анализ по методу n-d-M } \\
\hline & & \multirow[t]{2}{*}{ число колец К } & \multicolumn{2}{|c|}{ доля углеродных атомов, \% } \\
\hline & & & в кольцах & в цепях \\
\hline \multirow[t]{5}{*}{$350-420$} & Гюргянская & 2,3 & 45 & 55 \\
\hline & Косчагыльская & 1,9 & 39 & 61 \\
\hline & Грозненская & 1,6 & 34 & 66 \\
\hline & Ромашкинская & 1,7 & 36 & 64 \\
\hline & Нафрталанская & 2,7 & 59 & 41 \\
\hline \multirow[t]{4}{*}{$420-450$} & Гюргянская & 3,1 & 44 & 56 \\
\hline & Грозненская & 2,6 & 45 & 55 \\
\hline & Ромашкинская & 1,9 & 33 & 67 \\
\hline & Нафрталанская & 3,1 & 53 & 47 \\
\hline \multirow[t]{3}{*}{$500-525$} & Гюргянская & 3,4 & 38 & 62 \\
\hline & Косчагыльская & 2,6 & 28 & 73 \\
\hline & Нафрталанская & 3,6 & 58 & 42 \\
\hline \multirow[t]{2}{*}{ выше 525} & Гюргянская & 3,3 & 32 & 67 \\
\hline & Нафрталанская & 3,8 & 50 & 50 \\
\hline
\end{tabular}

Из-за повышения цикличности входящих во фракции молекул углеводородов происходит следующее: с увеличением температуры кипения фракций увеличиваются величины удельного веса (табл. 1). При сравнении составов нефтей выяснилось, что во всех случаях фракции нафталановой нефти имеют большую цикличность и в их молекулах доля углеводородов атомов в парафиновых цепях меньше, чем в другой любой нефти.

Состав некоторых фракций вакуумной перегонки нафталановой нефти также изучался методами дегидрогенизационного катализа, термодиффузии и спектрального анализа, адсорбционной хроматографии. Результаты изучения представлены в (таб. 3).

Из (табл. 3) можно наблюдать, что количество образующихся шестичленных структур преобладает над количеством недегидрирующихся циклопарафиновых углеводородов, при дегидрировании высококипящих фракций вакуумной перегонки, в отличие от низкокипящих фракций. А в результате дегидрирования фракций нафтеновых углеводородов нафталанской нефти образуется: меньше моноциклических (29-31\%) и больше полициклических ароматических углеводородов (35-43\%), во фракции других нефтей преимущественно образуются недегидрирующиеся углеводороды; 
дегидрирование последних показывает нам, что основную часть составляют моноциклические ароматические углеводороды (22-46\%)[6].

Таблица 3

\section{Результаты дегидрирования некоторых фракций нафтеновых углеводородов нафталанской нефти}

\begin{tabular}{|r|c|c|c|c|}
\hline $\begin{array}{c}\text { Пределы } \\
\text { кипения, }\end{array}$ & \multicolumn{5}{|c|}{ Выход углеводородов, \% на фракцию } \\
\cline { 2 - 5 } & $\begin{array}{c}\text { Циклопара- } \\
\text { финовых } \\
\text { углеводородов }\end{array}$ & $\begin{array}{c}\text { моноциклических } \\
\text { ароматических } \\
\text { углеводородов }\end{array}$ & $\begin{array}{c}\text { полициклических } \\
\text { ароматических } \\
\text { углеводородов }\end{array}$ & $\begin{array}{c}\text { сумма } \\
\text { ароматических } \\
\text { углеводородов }\end{array}$ \\
\hline $320-350$ & 74 & 12 & 14 & 26 \\
\hline $450-500$ & 33 & 31 & 35 & 66 \\
\hline $500-525$ & 28 & 29 & 43 & 72 \\
\hline выше 525 & 28 & 29 & 43 & 72 \\
\hline
\end{tabular}

Таблица 4

Результаты дегидрирования фракций различных нефтей

\begin{tabular}{|c|c|c|c|c|c|}
\hline \multirow{2}{*}{$\begin{array}{c}\text { Пределы } \\
\text { кипения, }{ }^{\circ} \mathrm{C}\end{array}$} & \multicolumn{5}{|c|}{ Выход углеводородов, \% на фрракцию } \\
\hline & Нефть & $\begin{array}{l}\text { Циклопара- } \\
\text { финовых } \\
\text { углеводо- } \\
\text { родов }\end{array}$ & $\begin{array}{l}\text { Моноцикли- } \\
\text { ческих аро- } \\
\text { матических }\end{array}$ & $\begin{array}{c}\text { Полицикличес- } \\
\text { ких аромати- } \\
\text { ческих угле- } \\
\text { водородов }\end{array}$ & $\begin{array}{c}\text { общее кол-во } \\
\text { ароматичесих } \\
\text { углеводородов }\end{array}$ \\
\hline $320-350$ & Нафрталанская & 74 & 12 & 14 & 26 \\
\hline $350-420$ & $\begin{array}{c}\text { Гюргянская } \\
\text { Косчагыльская } \\
\text { Грозненская } \\
\text { Ромашкинская }\end{array}$ & $\begin{array}{l}74 \\
67 \\
71 \\
70\end{array}$ & $\begin{array}{l}23 \\
27 \\
22 \\
24\end{array}$ & $\begin{array}{l}3 \\
6 \\
7 \\
6\end{array}$ & $\begin{array}{l}26 \\
33 \\
29 \\
30\end{array}$ \\
\hline $420-450$ & $\begin{array}{c}\text { Гюргянская } \\
\text { Грозненская } \\
\text { Ромашкинская }\end{array}$ & $\begin{array}{l}52 \\
49 \\
72\end{array}$ & $\begin{array}{l}34 \\
42 \\
22\end{array}$ & $\begin{array}{l}14 \\
9 \\
6\end{array}$ & $\begin{array}{l}48 \\
51 \\
28\end{array}$ \\
\hline $450-500$ & Нафрталанская & 33 & 32 & 35 & 67 \\
\hline $500-525$ & $\begin{array}{l}\text { Нафталанская } \\
\text { Гюргянская } \\
\text { Косчагыльская }\end{array}$ & $\begin{array}{l}31 \\
49 \\
63\end{array}$ & $\begin{array}{l}29 \\
46 \\
27\end{array}$ & $\begin{array}{c}40 \\
5 \\
10\end{array}$ & $\begin{array}{l}69 \\
51 \\
37\end{array}$ \\
\hline выше 525 & $\begin{array}{c}\text { Нафталанская } \\
\text { Гюргянская }\end{array}$ & $\begin{array}{l}28 \\
52\end{array}$ & $\begin{array}{l}29 \\
42\end{array}$ & $\begin{array}{c}43 \\
6\end{array}$ & $\begin{array}{l}72 \\
48\end{array}$ \\
\hline
\end{tabular}


Существует таблица элементарного и структурно-группового состава углеводородов нафталанской нефти [2]:

Таблица 5

\section{Элементарный и структурно-групповой состав углеводородов нафталана}

\begin{tabular}{|c|c|c|c|c|c|c|c|c|c|c|c|}
\hline \multirow[t]{3}{*}{$\begin{array}{l}\text { Группа } \\
\text { углеводородов }\end{array}$} & \multicolumn{7}{|c|}{ Структурно-групповой состав } & \multicolumn{3}{|c|}{$\begin{array}{l}\text { Элементарный } \\
\text { состав }\end{array}$} & \multirow{3}{*}{$\begin{array}{ll}\text { C/H } & \text { Общая } \\
\text { (средняя } & \text { формул } \\
\text { эмприческ а } \\
\text { ая } \\
\text { формула) }\end{array}$} \\
\hline & \multicolumn{3}{|c|}{ Число колец в молекуле } & \multicolumn{4}{|c|}{ Содержание углерода,\% } & \multirow[t]{2}{*}{$\mathrm{C}$} & \multirow[t]{2}{*}{$\mathrm{H}$} & \multirow[t]{2}{*}{$\mathrm{N}$} & \\
\hline & $\overline{\mathrm{K}_{\mathrm{o}}}$ & $\mathrm{K}_{\mathrm{a}}$ & $\mathrm{K}_{\mathrm{H}}$ & $\mathrm{C}_{\mathrm{K}}$ & $\mathrm{C}_{\mathrm{a}}$ & $\mathrm{C}_{\mathrm{H}}$ & $\mathrm{C}_{n}$ & & & & \\
\hline Нафтеновые & 2,5 & - & 2,5 & 59,0 & - & 59,0 & 41,0 & 86,29 & 13,71 & - & $\begin{array}{l}6,30\left(\mathrm{C}_{20,4} \quad \mathrm{C}_{n} \mathrm{H}_{2 n}-2,1\right. \\
\left.\mathrm{H}_{38,7}\right)\end{array}$ \\
\hline Ароматические: & & & 1,9 & & & & & & & & \\
\hline легкие & 2,8 & 0,9 & 2,0 & 55,7 & 23,4 & 32,1 & 44,0 & 87,90 & 12,10 & - & $\begin{array}{l}6,63\left(\mathrm{C}_{24,1} \mathrm{C}_{n} \mathrm{H}_{2 n}-8,3\right. \\
\left.\mathrm{H}_{30,5}\right)\end{array}$ \\
\hline средние & 3,5 & 1,5 & 1,6 & 75,8 & 37,9 & 37,1 & 24,2 & 89,48 & 10,52 & - & $\begin{array}{ll}8,51\left(\mathrm{C}_{23,6}\right. & \mathrm{C}_{n} \mathrm{H}_{2 n}-12,7 \\
\left.\mathrm{H}_{30,5}\right) & \end{array}$ \\
\hline тяжелые & 4,7 & 3,1 & 1,6 & 80,0 & & 24,4 & 20,0 & 90,31 & 9,69 & 0,95 & $\begin{array}{l}9,32\left(\mathrm{C}_{25,9} \mathrm{C}_{n} \mathrm{H}_{2 n}-18,5\right. \\
\left.\mathrm{H}_{33,3}\right)\end{array}$ \\
\hline
\end{tabular}

Говоря простыми словами, нафталанская нефть, в отличии от простой, не имеет в своем составе керосина и бензола. Она содержит фенолы, ароматические вещества, хлор, магний, серу и др. [7].

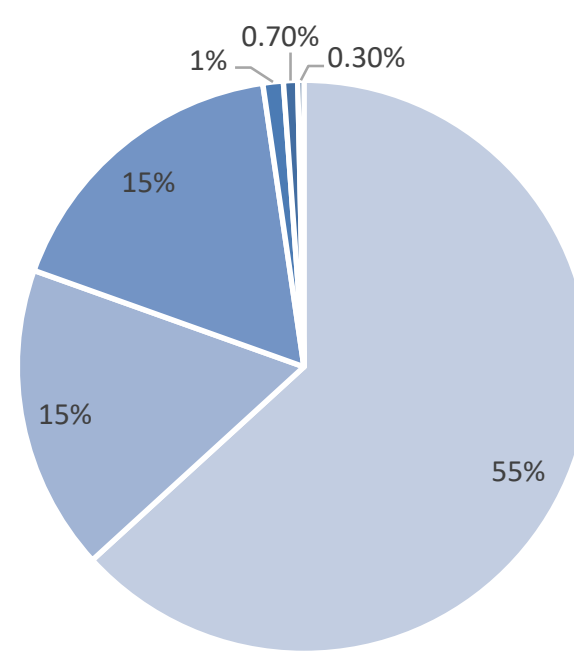

\footnotetext{
- Нафтановые углеводороды = Ароматические углеводороды - Смолистые вещества

- Нафтановые кислоты

- Cepa

- Азотистые соединения
}

Рис. 2. состав нафталанской нефти 


\section{Лечебные свойства нафталанской нефти}

Нафталановая нефть имеет обширный список лечебных свойств:

- Обезболивающее;

- Фунгицидное;

- Адаптогенное;

- Метаболическое;

- Фотозащитное;

- Противовоспалительное;

- Рассасывающее;

- Сосудорасширяющее;

- Регулирующее гормонообразование.

У нафталана большой спектр лечебного действия. Его используют в:

- Хирургии (для лечения травм нервной системы, трофических язв, ожогов);

- Стоматологии (при терапии пародонтоза);

- Неврологии (для лечения шейно-грудного и пояснично-крестцового радикулита);

- Гинекологии (для лечения бесплодия);

- Дерматологии (при лечении разных видов кожных заболеваний) и в других сферах.

В журнале [3] было опубликовано 65 формул, в состав которых входит нафталанская нефть.

Результаты клинических и экспериментальных исследований показывают высокую эффективность нафтеновых углеводородов при лечении двенадцатиперстной кишки и язвенной болезни желудка. По фармакологическим данным видно, что они имеют малую токсичность.

Очень интересным фактом является то, что нафталанская нефть воздействует на гипоталамус, который в свою очередь вырабатывает «гормон счастья» - серотонин. Нафталан нормализует работу эндокринной системы. После приема нескольких ванн уровень серотонина начинает колебаться: у человека может появиться бессонница/сонливость, а также наблюдаются перепады настроения. Такое состояние считается нормальным и говорит о том, что нафталанская нефть действует на гипоталамус. 


\section{Список литературы}

1. Исследование химического состава лечебной нафталанской нефти // Научные достижения биологии, химии, физики: сб. ст. по матер. VI междунар. науч.-практ. конф. - Новосибирск: СибАК, 2012.

2. Химический состав лечебной нафталанской нефти // А.Н. Мурадов, А.В. Анисимов .2006.

3. Журнал Pharm.Zeitung .1899.

4. Hazelwood R.N. // Analyt. Chem. 1954. 26. P. 1073.

5. Дидадзе А.В., Пустильникова С.А., Арефьев О.А., Петров А.А. // Нефтехимия. 1979.

6. Миронов В.А., Янковский С.А. Спектроскопия в органической химии. M., 1985.

7. Бранд Дж., Эглинтом Г. Применение спектроскопии в органической химии. М., 1967.

() Э.И. Субханкулова, 2021 